\title{
Heterogeneous Beliefs, Wealth Distribution and Asset Markets with Risk of Default
}

\author{
By Viktor Tsyrennikov*
}

We study asset markets and wealth dynamics in the economy with heterogeneous beliefs and risk of default. Agents can trade a full set of Arrow securities but are allowed to default on their asset delivery promises. Financial markets rationally subject agents to the endogenous 'no-default' borrowing limits. With complete financial markets speculation opportunities are plentiful. Financial wealth is volatile and the endogenous borrowing limits are always active. Variance of consumption and asset prices is amplified. Asset trading is substantial and volatile.

\section{The environment}

Time is discrete and indexed by $t \in \mathbb{Z}_{+}$. There is one perishable good in each date. The aggregate state of the economy is fully summarized by a stochastic process $s_{t}$ that is a first-order Markov process with a transition matrix $\Pi$. We let $s^{t}$ to denote the history of the state $\left(s_{0}, s_{1}, \ldots, s_{t}\right)$. Agents' beliefs about the state of the economy differ. We denote the transition probability matrix of agent $i$ by $\Pi^{i}$.

The economy is populated by two infinitely lived agents. Agent $i$ receives income $y^{i}\left(s_{t}\right)$ in period $t$ and state $s_{t}$. Agents can trade a full set of Arrow securities at each date and history. An Arrow security that pays one unit of good in state $k$ tomorrow trades at price $Q\left(s_{t+1}=k \mid s^{t}\right)$. There is limited contract enforcement. If an agent chooses to default on a contract she is forever banned from the financial market. ${ }^{1}$ Initial distribution of assets $\left\{a_{0}^{i}\left(s_{0}\right)\right\}_{i=1}^{I}$ is fixed.

Every agent chooses a consumption stream $\left\{c^{i}\left(s^{t}\right): \forall t, s^{t}\right\}$ to achieve the high-

* Cornell University, Economics Department, 452 Uris Hall, Ithaca, NY 14853; email: vt68@cornell.edu.

${ }^{1}$ It is trivial to allow for temporary market exclusion. est expected utility:

$$
U^{i}\left(s_{0} ; a_{0}\right)=\sum_{t=0}^{\infty} \sum_{s^{t}} \beta^{t} u\left(c^{i}\left(s^{t}\right)\right) \pi^{i}\left(s^{t} \mid s_{0}\right),
$$

subject to a sequence of budget constraints:

$c^{i}\left(s^{t}\right)+\sum_{s_{t+1}} Q\left(s^{t+1}\right) a^{i}\left(s^{t+1}\right)=y^{i}\left(s_{t}\right)+a^{i}\left(s^{t}\right)$.

Autarky. An agent living in autarky has no choices to make and simply consumes her income every period. We denote the life-time utility of agent $i$ living in autarky by $\underline{U}_{T}^{i}\left(s_{t}\right)$. It solves the following recursive equation:

$$
\underline{U^{i}}\left(s_{t}\right)=u\left(y^{i}\left(s_{t}\right)\right)+\beta E^{i}\left[\underline{U^{i}}\left(s_{t+1}\right) \mid s_{t}\right] .
$$

\section{Parameterization}

We assume that one period is a year and parameterize individual endowments to satisfy the following moments:

M1. $\sigma\left(\ln \left(y^{i}\left(s_{t}\right)\right)\right)=0.296$;

M2. $\operatorname{cor}\left(\ln \left(y^{i}\left(s_{t}\right)\right), \ln \left(y^{i}\left(s_{t-1}\right)\right)\right)=0.530$.

These are the estimates obtained by Heaton and Lucas (1996).

Moments M1 and M2 imply the following endowment states:

$$
\left(e^{1}, e^{2}\right)=\left[\begin{array}{c}
0.6438,0.3562 \\
0.3562,0.6438
\end{array}\right],
$$

and the following transition matrix:

$$
\Pi=\left[\begin{array}{ll}
0.7650 & 0.2350 \\
0.2350 & 0.7650
\end{array}\right] .
$$

Throughout we assume that $u(c)=$ $c^{1-\gamma} /(1-\gamma)$ with $\gamma=2$.

\section{Two special cases}

Alvarez and Jermann (2001) study the economy with homogeneous beliefs but im- 
perfect contract enforcement. The competitive equilibrium (CE) in such an environment is the same as in the economy with endogenous borrowing limits. Endogenous borrowing limits are wealth positions at which an agent is different between participating in the financial market or defaulting on her obligations. When individual income is relatively stable or discount factor is relatively low autarky is an attractive option. Endogenous borrowing limits bind in equilibrium. This leads to a volatile consumption and asset prices. Even with endogenous borrowing limits the competitive equilibrium is strongly stationary. That is the allocation, the price system and the wealth distribution are a function of the current exogenous state only. This severely limits the set of outcomes that can be obtained in this economy.

Blume and Easley (2006) show that in the model with perfect contract enforcement but heterogeneous beliefs agents consumption is a random walk. Since consumption is a monotone function of individual wealth the latter must inherit the properties of the consumption process. Agents participate in the financial markets for two reasons. First, to hedge fluctuations in individual income. Second, to speculate. Speculative motives arise because agents disagree about the evolution of the states. Since prices reflect beliefs of both agents

$$
\begin{aligned}
Q\left(k \mid s^{t}\right) & =\beta\left(e\left(s^{t+1}\right) / e\left(s^{t}\right)\right)^{-\gamma} \\
\times & {\left[\sum_{i=1}^{2} c^{i}\left(s^{t}\right) / e\left(s^{t}\right)\left(\pi^{i}\left(s_{t+1}=k \mid s^{t}\right)\right)^{1 / \gamma}\right]^{\gamma} }
\end{aligned}
$$

they always lie between the two subjective valuations. So, there is always trade even when individual incomes are the same. Speculative motive can dominate income hedging motive and it can lead to a highly volatile wealth and consumption. However, wealth and consumption move slowly when one of the agents is close to her natural borrowing limit. This constrains the model's ability to explain asset price volatility.

When beliefs are heterogeneous and the utility is unbounded below the endogenous borrowing limits always bind. ${ }^{2}$ Wealth and consumption are volatile because of speculation. The borrowing limits are tight and an agent can restore her financial wealth relatively quickly. So, speculative trade can proliferate. This is the link between the endogenous borrowing limits and the heterogeneous beliefs that we exploit.

\section{Hansen-Jaganathan bounds} by

$$
M\left(s^{t+1}\right)=\max _{i}\left[\beta \frac{u^{\prime}\left(c^{i}\left(s^{t+1}\right)\right)}{u^{\prime}\left(c^{i}\left(s^{t}\right)\right)}\right] .
$$

The equilibrium pricing kernel involves the highest IMRS in the economy as such agent must be unconstrained. Gross return $R\left(s^{t+1}\right)$ of any traded asset must then satisfy the following Euler equation:

$$
E^{i^{*}}\left[M\left(s^{t+1}\right) R\left(s^{t+1}\right) \mid s^{t}\right]=1,
$$

where $i^{*}$ is the index of the agent with the highest IMRS.

Using the Euler equation Hansen and Jaganathan (1991) derive restrictions on mean $\mu(M)$ and variance $\sigma(M)$ of the pricing kernel. The set of all admissible pricing kernels is represented by the shaded area in figure 1 . The boundary of this set is constructed using the average risk-free and equity returns reported in Mehra and Prescott (1985). A less restrictive test based on the data's average excess return implies that a pricing kernel must be above the dashed line.

Consider first the environment with homogeneous beliefs. Alvarez and Jerman (2001) show that the pricing kernel in the economy parameterized as above satisfies these bounds. This is achieved by assuming a very low discount factor $\beta=0.65$. With such a low discount factor autarky is a very attractive option, the endogenous borrowing limits are extremely tight and consumption is volatile. In fact the equilibrium

\footnotetext{
${ }^{2}$ For a proof see Tsyrennikov (2011).

${ }^{3}$ The same expression applies in the two special cases discussed above.
} 
a) HJ bounds

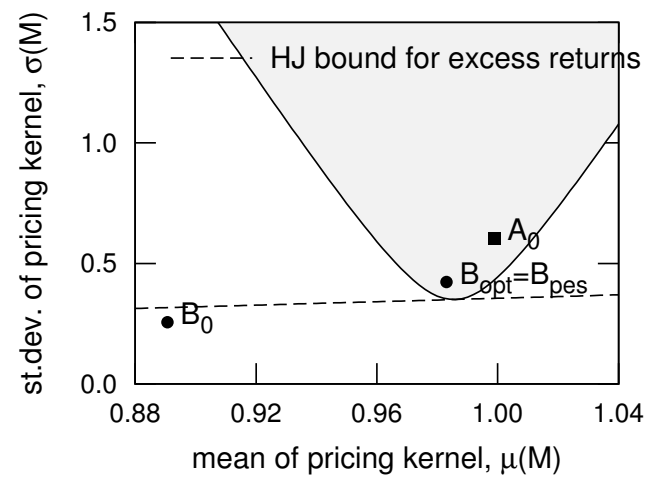

b) Detection error probability

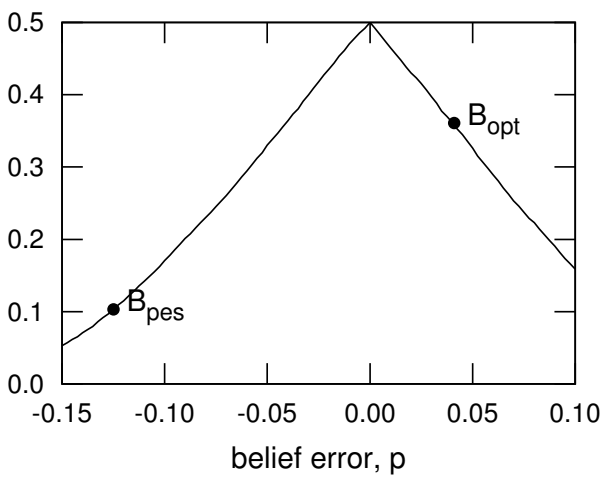

Figure 1. HANSEn-Jaganathan Bounds and DeteCtion-error probabilities

allocation is for all practical purposes identical to the autarkic allocation: maximal borrowing is under $0.09 \%$ of an agent's income. Such a low discount factor is also inconsistent with the majority of macroeconomics research assuming $\beta \geqslant 0.95$.

Alvarez and Jermann's pricing kernel is denoted by point $A_{0}$ in figure 1 . When we increase the discount factor the point moves in the south-west direction outside the HJ region. Larger discount factor reduces the autarkic utility or, equivalently, relaxes the borrowing limits. As we increase the discount factor the equilibrium pricing kernel's variance decreases and eventually the pricing kernel degenerates into a constant, $M\left(s^{t+1}\right)=\beta$. This happens at $\beta=0.8405$.

Consider now the case with an intermediate discount factor $\beta=0.75$. It corresponds to the point $B_{0}$ in figure 1 . The borrowing limit is $14.7 \%$ of annual income in high income state and $25.0 \%$ in low-income state. However, the pricing kernel does not satisfy the HJ bounds. It also lies outside the HJ bounds for excess returns. Because the agents are more patient the autarky value is relatively low and the endogenous borrowing limits nearly unrestrictive.

By introducing diverse beliefs we can bring the pricing kernel back into the HJ acceptance region. We parameterize individual beliefs by a parameter $p$. When $p>0$ we set

$\Pi^{1}=\Pi+\left[\begin{array}{cc}p & -p \\ 0 & 0\end{array}\right], \Pi^{2}=\Pi+\left[\begin{array}{cc}0 & 0 \\ -p & p\end{array}\right]$

In this case agents are optimistic as they overestimate persistence of good state. When $p<0$ we set

$\Pi^{1}=\Pi+\left[\begin{array}{cc}0 & 0 \\ -p & p\end{array}\right], \Pi^{2}=\Pi+\left[\begin{array}{cc}p & -p \\ 0 & 0\end{array}\right]$

In this case agents are pessimistic. We measure plausibility of the individual beliefs by the detection-error probability (dep) defined in Hansen and Sargent (2008). When $\operatorname{dep}=0.5$ then the two models under consideration are indistinguishable. The models are inconsistent with each other when $\operatorname{dep}=0$.

Point $B_{\text {pes }}=B_{\text {opt }}$ corresponds to either $p=-0.125$ or $p=0.041 .^{4}$ Either form of belief heterogeneity, optimism or pessimism, increases volatility of the pricing kernel. However, optimistic agents value autarky highly and the endogenous borrowing limits are tight. An agent can borrow $5.4 \%$ when her income is high and $9.7 \%$ when her income is low. This is still 100 times larger than the borrowing limit corresponding to point $A_{0}$. Tight borrowing limits increase volatility of the pricing kernel. Pessimistic agents, on the other hand, face close.

${ }^{4}$ These are two distinct points that are numerically 
relatively generous borrowing limits. Maximal borrowing is at least $39.2 \%$ of one's income. So, there must be a significant belief heterogeneity to counter the unrestrictive borrowing limits.

Figure 1 panel (b) shows that the optimistic model's dep is 0.361 . But the pessimistic model's dep is a mere 0.103. Despite the unlikeliness of such extreme pessimism these results demonstrate that belief diversity allows bringing the model's pricing kernel in line with the data.

\section{Wealth evolution and trade volume}

We now turn to wealth evolution and trading volume in the economy with heterogeneous beliefs. We set $\gamma=2, \beta=0.95$. We choose $\beta=0.95$ to demonstrate that the model can generate interesting wealth dynamics even with patient consumers. We assume that consumers are pessimistic and set $p=-0.074$. Individual beliefs are reasonably difficult to distinguish $(\mathrm{dep}=0.25)$ from the true model. The initial state is $s_{0}=1$. We set initial asset position $a^{1}\left(s_{0}\right)=-0.2897$ to assure an equal consumption for both agents.

Two forces drive wealth evolution in the economy with diverse beliefs. First, an agent buys Arrow securities for the states in which her income is low. Second, she buys additional Arrow securities for the same state because she overestimates its probability. The latter trades are speculative as they are undertaken only when beliefs are diverse.

Figure 2 panel (a) plots dynamics of agent 1's wealth with homogeneous and diverse beliefs. Dashed line corresponds to the baseline economy with homogeneous beliefs and the endogenous borrowing limits (EBL). Because the discount factor is sufficiently high endogenous borrowing limits are inoperative. Changes in wealth mirror those in individual income. Wealth does not change unless the state of the economy changes. Solid line represents the economy with heterogeneous beliefs and the EBL. When we add heterogeneous beliefs wealth volatility increases 4.18 times. Wealth changes even if the state of the econ- omy is the same. The competitive allocation is now history dependent.

Figure 2 panel (b) shows dynamics of consumer 1's consumption. With homogeneous beliefs consumption is constant and equals 0.5 . With heterogeneous beliefs consumption responds to changes in agent 1's wealth. A pessimistic agent 1 invests in Arrow security that pays in state 1 when her income is low. When state 1 occurs agent 1 's financial wealth and consumption increase.

We now turn to asset 'quantities,' that is trading volume. We define trading volume as follows:

$$
\operatorname{vol}\left(s^{t}\right)=\sum_{s_{t+1}} Q\left(s_{t+1} \mid s^{t}\right)\left|a^{1}\left(s^{t+1}\right)\right| .
$$

It is significant and very volatile in the economy with heterogeneous beliefs. In the economy with homogeneous beliefs trading volume is small and constant over time. Portfolio of each agent oscillates between two symmetric values. ${ }^{5}$

Finally, we compute the return to the asset that pays aggregate endowment as dividend. When beliefs are homogeneous the price of this asset is constant the return equals $1 / \beta$ at all times. When beliefs are heterogeneous the asset price is higher due to speculative demand. The asset price is relatively low when wealth distribution is equal. ${ }^{6}$ In this case speculative demand is low as the asset price is midway between the two subjective valuations. Asset return is high when the financial wealth inequality increases and the price increases above the 'normal' level. Asset return is low when financial inequality decreases and the price decreases to the normal level. ${ }^{7}$

\footnotetext{
${ }^{5}$ Our result is stronger when only long-term securities are traded. Judd et al. (2003) show that when beliefs are homogeneous then portfolios are constant. So, trading volume is zero. Portfolios are not constant with heterogeneous beliefs.

${ }^{6}$ That is wealth of agent 1 is close to zero.

${ }^{7}$ Despite high variance of the return the pricing kernel is not sufficiently volatile and lies outside of the HJ bounds.
} 
a) Wealth of agent 1

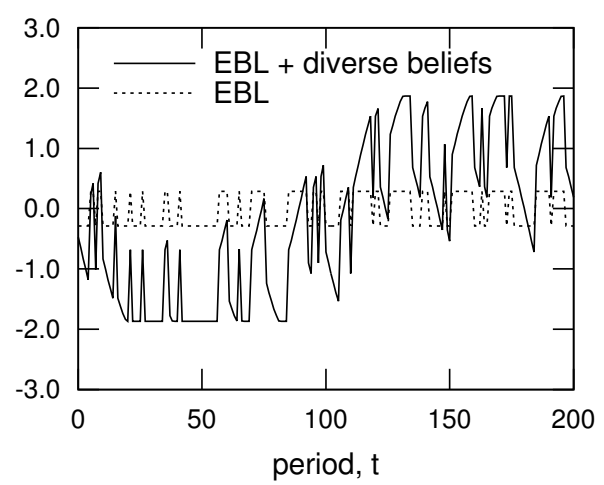

c) Trading volume

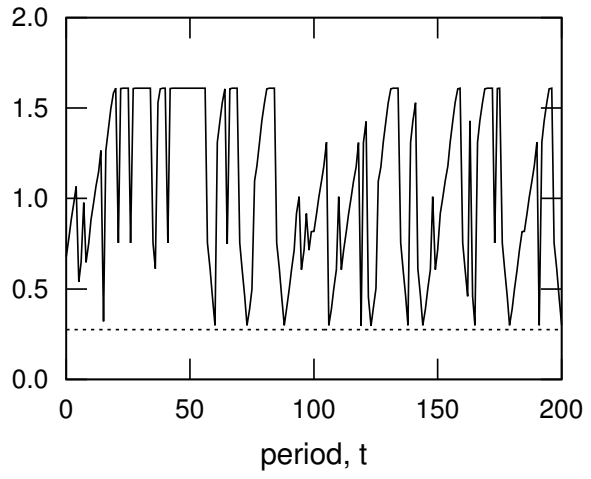

b) Consumption of agent 1

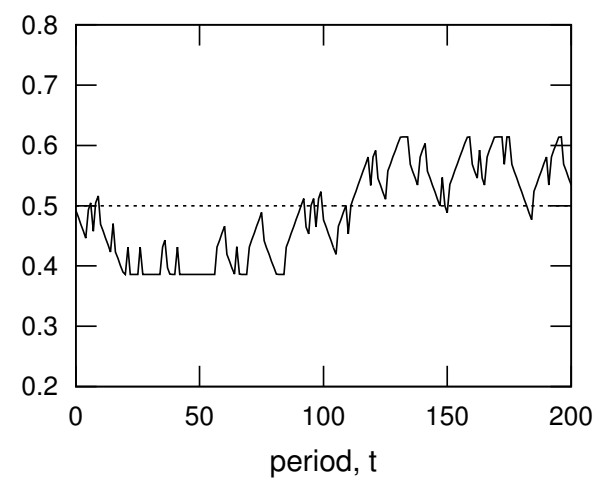

d) Returns

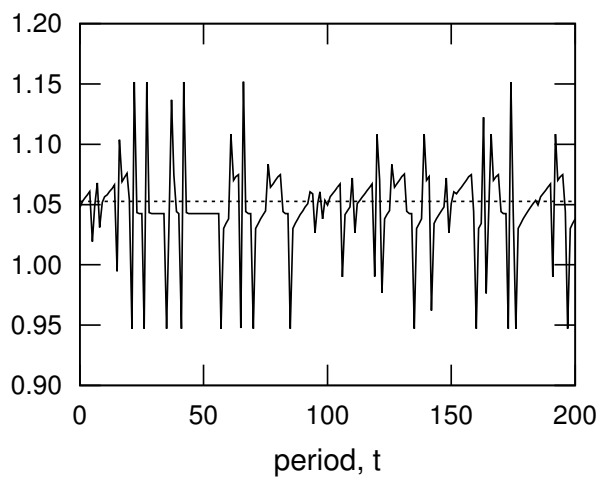

Figure 2. Dynamics of Wealth, CONSumption, Returns

\section{Conclusions}

We study asset markets and wealth dynamics in the economy with heterogeneous beliefs and risk of default. We demonstrate how the endogenous 'no-default' borrowing limits interact with heterogeneous beliefs to create a volatile trading environment. Unlike with homogeneous beliefs the endogenous borrowing limits are always active. Wealth and consumption variance are amplified leading to highly volatile asset prices. Trading volume is substantial and also highly volatile.

\section{References}

Alvarez, F. and U. Jermann, 2001, Quantitative Asset Pricing Implications of Endogenous Solvency Constraints, Review of Financial Studies, 14, 1117-1151.

Blume, L. and D. Easley, 2006, If You're So Smart, Why Aren't You Rich? Belief
Selection in Complete and Incomplete Markets, Econometrica 74, 929-966.

Cogley T., T. Sargent and V. Tsyrennikov, 2011, Wealth Dynamics in a Bond Economy with Heterogeneous Beliefs, manuscript.

Hansen, L. and R. Jagannathan, 1991, Implications of Security Market Data for Models of Dynamic Economies, Journal of Political Economy 91, 225-262.

Heaton J. and D. Lucas, 1996, Evaluating the Effects of Incomplete Markets on Risk Sharing and Asset Pricing, Journal of Political Economy 104, 443-487.

Judd K., F. Kubler, and K. Schmedders, 2003, Asset Trading Volume with Dynamically Complete Markets and Heterogeneous Agents, Journal of Finance 58, 2203-2218.

V. Tsyrennikov, 2011, Asset Markets with Diverse Beliefs and Risk of Default, manuscript. 